\title{
Walking and examining the patient before running to the imaging tests
}

\author{
Alberto Alain Gabbai ${ }^{1}$
}

With the advent of brain imaging modalities, starting with CT scans and evolving to the MRI (with increasing Tesla potencies), MRA, functional MRI, PET scan, and now with impressively more sophisticated integrated image analysis, like quantitative analysis of complex networks, that integrate with mathematical models, structural and functional MRI, diffusion tensor imaging, magnetoencephalography and electroencephalography ${ }^{1}$, one may wonder why should we ever have to examine a patient again.

Let us not forget that it is common for neurologists to be called upon for a consultation on a patient that has all normal images, but is still sick, being it a continuous headache, a weakness somewhere, a movement disorder, a double vision, a clouding of consciousness, a dizziness, or an abnormal gait.

The neurologic examination still remains an essential part of the neurologic consultation. After centuries of improvement ${ }^{2}$ it has also become extensive and sophisticated and it is the basis upon which most of the ancillary tests are to be ordered.

As recently shown, with clinical assessments only (neuroimaging did not alter the diagnosis), it was possible to make the diagnosis of frontotemporal lobar degeneration with $100 \%$ sensitivity and $97 \%$ specificity and Alzheimer's disease with $97 \%$ sensitivity and $100 \%$ specificity in 228 patients whose brains were subsequently examined at post-mortem ${ }^{3}$.

Péricles Maranhão-Filho and colleagues show in this issue of the Arquivos ${ }^{4,5}$ that just one part of the neurologic examination, the balance (static and dynamic) assessment, has also become rather refined over the last decades and properly executed brings diagnoses that may lead to effective treatments or interventions that can markedly diminish morbidity and mortality from falls. Moreover, most of the diagnoses that can accurately be made with a precise balance assessment cannot be made with routine imaging modalities.

The difficult problem of differentiating early stages of Parkinson's disease from other progressive Parkinsonian syndromes can be accomplished with details of balance and gait: tandem gait and cycling ${ }^{6,7}$, and the arduous differential diagnosis of dizziness can be much helped with all the tests presented in this issue by Péricles Maranhão-Filho and colleagues ${ }^{4,5}$.

Other Brazilian authors have also studied gait and balance disorders in specific diseases:

Antonio Pedro Vargas and colleagues ${ }^{8}$ have shown the clinical characteristics of two patients with psychogenic gait abnormalities and the difficult differential diagnosis; Roberta de Melo Roiz and colleagues ${ }^{9}$ have shown, using kinematics data, that in 12 patients with Parkinson's disease (compared to 15 controls) there was a lower stride velocity, shorter stride length and slower hip joint kinematics; and Eliane Mayumi Kato-Narita and colleagues ${ }^{10}$ have shown that in 48 patients with mild and moderate Alzheimer's disease (AD) (compared to 40 normal subjects) there was a decline of balance asso-

\section{EXAMINEMOS O EQUILÍBRIO E A MARCHA ANTES DE CORRER DIRETAMENTE PARA OS PEDIDOS DE IMAGENS}

${ }^{1} \mathrm{MD}$, PhD Full Professor of Neurology. Escola Paulista de Medicina, Universidade Federal do Estado de São Paulo, São Paulo SP, Brazil. 
ciated to the occurrence of falls, but interestingly the loss of functional capacity was associated with the disease's progression but not with a higher occurrence of falls.

Péricles Maranhão-Filho and colleagues ${ }^{4,5}$ are to be commended for bringing back the fundamental issue of the neurologic examination and for explaining in details how to perform and correctly interpret a modern and elegant evaluation of stance and gait.

\section{REFERENCES}

1. Bullmore E, Sporns O. Complex brain networks: graph theoretical analysis of structural and functional systems. Nat Rev Neurosci 2009;10:186-198. Erratum in: Nat Rev Neurosci 2009;10:312.

2. Fine EJ, Ziad Darkhabani M. Chapter 16: History of the development of the neurological examination. Handb Clin Neurol 2010;95:213-233.

3. Snowden JS, Thompson JC, Stopford CL, et al. The clinical diagnosis of early-onset dementias: diagnostic accuracy and clinicopathological relationships. Brain 2011;134:2478-2492.

4. Maranhão-Filho P, Maranhão ET, da Silva MM, Lima MA. Rethinking the Neurological Examination I: Static Balance Assessment. Arq Neuropsiquiatr 2011;69:954-958

5. Maranhão-Filho P, Maranhão ET, Lima MA, da Silva MM. Rethinking the Neurological Examination II: Dynamic Balance Assessment. Arq Neuropsiquiatr 2011;69:959-963

6. Abdo WF, Borm GF, Munneke M, Verbeek MM, Esselink RA, Bloem BR. Ten steps to identify atypical parkinsonism. J Neurol Neurosurg Psychiatry 2006; 77:1367-1369.

7. Snijders AH, Toni I, Ruzicka E, Bloem BR. Bicycling breaks the ice for freezers of gait. Mov Disord 2011;26:367-371.

8. Vargas AP, Carod-Artal FJ, Del Negro MC, Rodrigues MP. [Psychogenic dystonia: report of 2 cases]. Arq Neuropsiquiatr 2000;58:522-530.

9. Roiz Rde M, Cacho EW, Pazinatto MM, Reis JG, Cliquet Ajr, BarasneviciusQuagliato EM. Gait analysis comparing Parkinson's disease with healthy elderly subjects. Arq Neuropsiquiatr 2010;68:81-86.

10. Kato-Narita EM, Nitrini R, Radanovic M. Assessment of balance in mild and moderate stages of Alzheimer's disease: implications on falls and functional capacity. Arq Neuropsiquiatr 2011;69:202-207. 